(2) $\begin{array}{r}2017 \text { Volume 23(3): 441-461 } \\ \text { doi:10.3846/20294913.2015.1072754 }\end{array}$

\title{
NEW GROUP DECISION MAKING METHOD IN INTUITIONISTIC FUZZY SETTING BASED ON TOPSIS
}

\author{
Wei YANG ${ }^{\mathrm{a}, \mathrm{b}}$, Zhiping CHEN $^{\mathrm{a}}$, Fang ZHANG $^{\mathrm{a}}$ \\ ${ }^{a}$ Department of Computing Science, School of Mathematics and Statistics, \\ Xian Jiaotong University, 710049 Xian, Shaanxi, P. R. China \\ ${ }^{b}$ Department of Mathematics, School of Science, Xi'an University of Architecture and Technology, \\ 710055 Xian, Shaanxi, P. R. China
}

Received 03 December 2013; accepted 24 June 2014

\begin{abstract}
In multiple attribute group decision making, the weights of decision makers are very crucial to ranking results and have gained more and more attentions. A new approach to determining experts' weights is proposed based on the TOPSIS (Technique for Order Preference by Similarity to an Ideal Solution) method in intuitionistic fuzzy setting. The weights determined by our method have two advantages: the evaluation value has a large weight if it is close to the positive ideal evaluation value and far from negative ideal evaluation values at the same time, otherwise it is assigned a small weight; experts have different weights for different attributes, which are more appropriate for real decision making problems since each expert has his/her own knowledge and expertise. The multiple attribute intuitionistic fuzzy group decision making algorithm has been proposed which is suitable for different situations about the attribute weight information, including the attribute weights are known exactly, partly known and unknown completely. A supplier selection problem and the evaluation of murals in a metro line are finally used to illustrate the feasibility, efficiency and practical advantages of the developed approaches.
\end{abstract}

Keywords: multiple attribute group decision making, intuitionistic fuzzy set, TOPSIS, weight.

JEL Classification: C02, C52, C61.

\section{Introduction}

In the decision making process, experts usually can not provide exact evaluation values since the decision making problem has become rather complicated and much professional knowledge is needed. Hence some extent of hesitation has been expressed during the evaluating process. Many useful tools have been developed to model uncertain information including fuzzy set (Zadeh 1965; Merigó, Gil-Lafuente 2011), intuitionistic fuzzy set (IFS) (Atanassov 1986), intuitionistic fuzzy soft set (Maji et al. 2001; Jiang et al. 2013), linguistic

Corresponding author Zhiping Chen

E-mail: zchen@mail.xjtu.edu.cn 
arguments (Herrera et al. 1995; Merigó, Gil-Lafuente 2013), etc. As a generalization of fuzzy set, IFS is more appropriate for modelling uncertainty and hesitation and has been studied and applied extensively, many decision making methods in intuitionistic fuzzy setting (Atanassov et al. 2005; Chen, Yang 2011a; Chen, Tan 1994; Hong, Choi 2000; Li et al. 2009; Liu, Wang 2007; Su et al. 2011; Szmidt et al. 2014; Wei, Merigó 2012; Yang, Chen 2012; Xu 2007; Xu, Liao 2015) have been developed. In order to better model uncertainty existing in the decision making process, the alternatives are evaluated by intuitionistic fuzzy values in this paper.

With the development of science and technology, it is less and less possible for a single decision maker to consider all aspects of a decision problem. Hence, in order to make scientific and reasonable decisions, multiple decision makers are involved in the decision making process, the corresponding problem is a multiple attribute group decision making (MAGDM) problem. For simplicity, experts' weights are often assigned in advance (Chen, Niou 2011; Chuu 2009; Hajiagha et al. 2013; Liu 2011, 2012; Pang, Liang 2012; Ran, Wei 2015; Xu 2010; Xu et al. 2012; Wei 2011) or equal weights (Chen et al. 2012; Chen, Yang 2011b; Lin et al. 2008; Su et al. 2013; Wang et al. 2012; Wei 2011; Wu, Chen 2007) are taken in group decision making, whose shortcomings are obvious. For the complex decision making problem, decision makers usually come from different fields. Since each expert has his/her characteristics, special knowledge, skills and expertise, he/she may be familiar with some attributes but not so familiar with others. For those unfamiliar attributes, decision maker may give unduly high or low evaluation values. If each expert uses the same weight for all the attributes, unreasonable decision results can be deduced and incorrect alternative might be selected. Therefore, how to determine reasonable weights for experts becomes an important and interesting research topic, which has attracted extensively attentions (Brock 1980; Keeney, Kirkwood 1975; Kim et al. 1999; Li 2007; Olcer, Odabasi 2005; Ramanathan, Ganesh 1994; Yue 2011, 2012; Wei 2011). Olcer and Odabasi (2005) transformed experts' opinions into a group consensus opinion by using the homogeneous method, in which experts are assigned different weights for different alternatives. But if the number of experts is very large, the method needs a lot of computations and poor accuracy may result in. The interpersonal comparisons are used in Keeney and Kirkwood (1975) to obtain values for the scaling constants in the weighted additive social choice function. An approach based on Nash bargaining (Brock 1980) is used to estimate the weights of group members. An interactive procedure is proposed by Kim et al. (1999) for solving a MAGDM problem with incomplete information, in which each group member's utility information is compared with that of a group and is then aggregated into a group one. If there are many attributes and alternatives, too many interactions have to be considered. The linguistic weighting vector has been given by Wei (2010) to represent importance. An eigenvector method is used by Ramanathan and Ganesh (1994) to determine the weights of group members by using their own subjective opinions. Yue (2011) has developed a new method to determine experts' weights by using the TOPSIS method, in which weights are calculated by using the distance of evaluation values to the positive ideal solution, the left negative ideal solution and the right negative ideal solution, respectively. In Yue (2012), the weights of decision makers are determined by using both the positive ideal decision and negative ideal deci- 
sion. Though many MAGDM methods have been proposed in intuitionistic fuzzy setting, experts have the same weights for all the attributes in most of studies or have been assigned different weights for different attributes. In the latter case, the characteristics of experts should be examined, but then the computation amount is too large and this might result in poor accuracy, especially for the situation that the number of alternatives and attributes is extremely large.

TOPSIS is proposed by Hwang and Yoon (1981), which has been studied and applied widely (Boran et al. 2009; Chen, Yang 2011a; Dymova et al. 2015; Liu et al. 2013; Lourenzutti, Krohling 2014; Park et al. 2011; Patil, Kant 2014; Tan 2011; Taylan et al. 2014; Ye 2010; Zhang, Yu 2012). In TOPSIS, a good alternative is the one that is nearest to the positive ideal alternative, and at the same time, is farthest from the negative ideal alternative. Chen and Yang (2011a) use the constrained fuzzy analytic hierarchy process to determine attribute weights and rank the alternatives by using the fuzzy TOPSIS. Park et al. (2011) extend TOPSIS to solve MAGDM problems with interval-valued intuitionistic fuzzy information, in which the attribute weights are partly known. Zhang and Yu (2012) set up an optimization model to determine attribute weights by using the fuzzy cross-entropy and use TOPSIS to rank the alternatives. Tan (2011) develops an interval-valued intuitionistic fuzzy group decision making method based on TOPSIS by using Choquet integral-based Hamming distance. In this study, we develop a new multiple group decision making method with intuitionistic fuzzy information by using the idea of TOPSIS. In order to aggregate different evaluation values into a reasonably collective one, we first define the average value of different evaluation values as the positive ideal solution, the maximum and minimum of evaluation values as the negative ideal solutions, then the distances of each evaluation value to the positive and negative ideal solutions, respectively, can be determined, the closeness coefficients are finally calculated by using the TOPSIS method, and the weights of evaluation values can be obtained by normalizing closeness coefficients. The weights determined by our new method have the following advantages: the evaluation value has a big weight if it is close to the positive ideal evaluation value and is far from negative ideal evaluation values; otherwise, the evaluation value is assigned a small weight. The influence of unduly high or low evaluation values on the ranking result is thus reduced. According to different situations about the attribute weight information, that is, the attributes are known exactly, partly known or unknown completely, we design the corresponding decision making algorithm. If attribute weights are known exactly, the TOPSIS method is used to rank alternatives after aggregating different experts' evaluation values into a collective one by using the new method; if attribute weights are known partly, a linear programming model is set up to determine the attribute weights; if attribute weights are unknown completely, they are then determined by using the TOPSIS method. Finally, the new algorithm is applied to a supplier selection problem and a case study to illustrate their efficiency and practical advantages.

In order to do so, the rest of this paper is organized as follows. Some concepts about IFS are introduced in the next section. In Section 2, the new method to determine experts' weights by utilizing the TOPSIS method is developed, then different attribute weight information situations are considered, and the corresponding algorithm is presented. Two numerical examples are presented to illustrate our new algorithm in Section 3. The conclusions are given in the last section. 


\section{Basic concepts}

As a preparation for introducing our new method, some relevant concepts are illustrated in this section.

Definition 1 (Atanassov 1986). Let $X$ be a fixed set, an IFS $A$ in $X$ is defined as:

$$
A=\left\{<x, \mu_{\mathrm{A}}(x), v_{\mathrm{A}}(x)>\mid x \in X\right\},
$$

where the functions $\mu_{\mathrm{A}}(x): X \rightarrow[0,1], v_{\mathrm{A}}(x): X \rightarrow[0,1]$ are the degrees of membership and nonmembership of an element $x \in X$, respectively, they satisfy $0 \leq \mu_{\mathrm{A}}(x)+v_{\mathrm{A}}(x) \leq 1$, $\forall x \in X . \pi_{A}(x)=1-\mu_{\mathrm{A}}(x)-v_{\mathrm{A}}(x)$ is called the intuitionistic fuzzy index of $x \in A$. It represents the degree of indeterminacy or hesitation of $x \in A$. For each $x \in X, 0 \leq \pi_{A}(x) \leq 1$.

Each fuzzy set can be represented as the following intuitionistic fuzzy set:

$$
A=\left\{<x, \mu_{\mathrm{A}}(x), 1-\mu_{\mathrm{A}}(x)>\mid x \in X\right\} .
$$

For an IFS $A$, the pair $\left(\mu_{\mathrm{A}}(x), v_{\mathrm{A}}(x)\right)$ is called an intuitionistic fuzzy value (IFV). For notational convenience, we denote in what follows an IFV by $\alpha=(\mu, v)$, where $\mu \in[0,1]$, $v \in[0,1], \mu+v \leq 1$. $\Omega$ is the set of all the IFVs.

Let $\alpha_{1}=\left(\mu_{1}, v_{1}\right), \alpha_{2}=\left(\mu_{2}, v_{2}\right)$ and $\alpha=(\mu, v)$ be three IFVs, then the operational laws of IFVs (Xu 2007) can be defined as follows:

1) $\alpha_{1}+\alpha_{2}=\left(\mu_{1}+\mu_{2}-\mu_{1} \mu_{2}, v_{1} v_{2}\right)$,

2) $\lambda \alpha=\left(1-(1-\mu)^{\lambda}, v^{\lambda}\right), \lambda>0$.

Let $\alpha=(\mu, v)$ be an IFV, then the score function (Chen, Tan 1994) of $\alpha$ is defined as $s(\alpha)=\mu-v$, where $s(\alpha) \in[-1,1]$. The bigger the score of $s(\alpha)$ is, the larger the IFV of $\alpha$ is. The accuracy function (Hong, Choi 2000) of an IFV $\alpha=(\mu, v)$ is defined as $h(\alpha)=\mu+v$, where $h(\alpha) \in[0,1]$. The larger the $h(\alpha)$ is, the higher accuracy degree of $\alpha$ is.

Based on the score function and the accuracy function, the following method is proposed by $\mathrm{Xu}$ (2007) to compare two IFVs.

Definition 2. Let $\alpha_{1}=\left(\mu_{1}, v_{1}\right)$ and $\alpha_{2}=\left(\mu_{2}, v_{2}\right)$ be two IFVs.

If $s\left(\alpha_{1}\right)<s\left(\alpha_{2}\right)$, then $\alpha_{1}$ is smaller than $\alpha_{2}$, denoted by $\alpha_{1}<\alpha_{2}$;

If $s\left(\alpha_{1}\right)=s\left(\alpha_{2}\right)$, and

1) if $h\left(\alpha_{1}\right)<h\left(\alpha_{2}\right)$, then $\alpha_{1}$ is smaller than $\alpha_{2}$, denoted by $\alpha_{1}>\alpha_{2}$;

2) if $h\left(\alpha_{1}\right)=h\left(\alpha_{2}\right)$, then $\alpha_{1}$ and $\alpha_{2}$ represent the same information, denoted by $\alpha_{1}=\alpha_{2}$.

Definition $3(\mathrm{Xu} 2010)$. Let $\alpha_{1}=\left(\mu_{1}, v_{1}\right)$ and $\alpha_{2}=\left(\mu_{2}, v_{2}\right)$ be two IFVs, then:

$$
d\left(\alpha_{1}, \alpha_{2}\right)=\frac{1}{2}\left(\left|\mu_{1}-\mu_{2}\right|+\left|v_{1}-v_{2}\right|\right)
$$

is defined as the distance between $\alpha_{1}$ and $\alpha_{2}$. 


\section{New MAGDM algorithm in intuitionistic fuzzy setting}

In the decision making process, several experts, who may come from different departments, are involved in order to get scientific decisions. Assume that there is a multiple attribute group decision problem as follows. Let $\left\{E_{1}, E_{2}, \ldots, E_{t}\right\}$ be the set of experts, $\left\{A_{1}, A_{2}, \ldots, A_{m}\right\}$ be the set of alternatives and $\left\{B_{1}, B_{2}, \ldots, B_{n}\right\}$ be the set of attributes. The expert $E_{k}$ evaluates the alternative $A_{i}$ with respect to the attribute $B_{j}$ to get the evaluation value $\alpha_{i j}^{(k)}=\left(\mu_{i j}^{(k)}, v_{i j}^{(k)}\right)$ $(k=1,2, \ldots, t)$, then the decision matrix $D^{(k)}$ is formed as:

$$
D^{(k)}=\left(\alpha_{i j}^{(k)}\right)_{m \times n}=\left(\begin{array}{cccc}
\alpha_{11}^{(k)} & \alpha_{12}^{(k)} & \ldots & \alpha_{1 n}^{(k)} \\
\alpha_{21}^{(k)} & \alpha_{22}^{(k)} & \ldots & \alpha_{2 n}^{(k)} \\
\ldots & \ldots & \vdots & \ldots \\
\alpha_{m 1}^{(k)} & \alpha_{m 2}^{(k)} & \ldots & \alpha_{m n}^{(k)}
\end{array}\right) .
$$

During the decision making process, different decision matrices should be first aggregated into a collective one.

With the development of science and technology, the decision problem becomes more and more complicated. There are too many alternatives to be selected and many decision makers are involved to select the optimal alternative. At the same time, decision makers have their own knowledge and expertise and can not master all the knowledge needed in the decision making, they may be familiar with some attributes but not familiar with others, hence they might give unduly high or low evaluation values. If experts are assigned the same weight for all the attributes, unreasonable results can result in. Meanwhile, each expert has his/her characteristics for the specific knowledge and expertise. If the expert is familiar with or is a specialist in the attribute, he/she can give a reasonable evaluation value, hence a big weight should be assigned to the attribute. If the decision maker is not familiar with the attribute, a small weight should be assigned. Then different experts should have different weights for different attributes. If each expert's characteristics are investigated in order to assign reasonable weights for the attributes, the resulting computation amount is too large and can lead to poor accuracy. TOPSIS is an extensively used method in the real decision making. In TOPSIS, the alternatives are ranked by the size of closeness coefficients calculated by using the positive ideal solution and negative ideal solutions. In order to avoid the influence of unduly high or low evaluation values on ranking results, the evaluation values which are close to the positive ideal evaluation value and far from negative ideal evaluation values at the same time should have large weights, and the evaluation values should have small weights in other cases. Therefore, the average evaluation value can be seen as an intuitionistic fuzzy positive ideal evaluation value like that in Yue (2011). In this way, the intuitionistic fuzzy positive ideal matrix can be defined as:

$$
D^{+}=\left(\alpha_{i j}^{+}\right)_{m \times n}=\left(\begin{array}{cccc}
\alpha_{11}^{+} & \alpha_{12}^{+} & \ldots & \alpha_{1 n}^{+} \\
\alpha_{21}^{+} & \alpha_{22}^{+} & \ldots & \alpha_{2 n}^{+} \\
\ldots & \ldots & \vdots & \ldots \\
\alpha_{m 1}^{+} & \alpha_{m 2}^{+} & \ldots & \alpha_{m n}^{+}
\end{array}\right),
$$


where $\alpha_{i j}^{+}=\left(\sum_{k=1}^{t} \alpha_{i j}^{(k)}\right) / t, i=1,2, \ldots, m, j=1,2, \ldots, n, k=1,2, \ldots, t$, are intuitionsitic fuzzy positive ideal solutions (IFPISs). The intuitionistic fuzzy negative ideal matrices can be divided into the following two parts $D_{d}^{-}$and $D_{u}^{-}$:

$$
\begin{gathered}
D_{d}^{-}=\left(\alpha_{i j}^{d}\right)_{m \times n}=\left(\begin{array}{cccc}
\alpha_{11}^{d} & \alpha_{12}^{d} & \ldots & \alpha_{1 n}^{d} \\
\alpha_{21}^{d} & \alpha_{22}^{d} & \ldots & \alpha_{2 n}^{d} \\
\ldots & \ldots & \vdots & \ldots \\
\alpha_{m 1}^{d} & \alpha_{m 2}^{d} & \ldots & \alpha_{m n}^{d}
\end{array}\right) ; \\
D_{d}^{-}=\left(\alpha_{i j}^{u}\right)_{m \times n}=\left(\begin{array}{cccc}
\alpha_{11}^{u} & \alpha_{12}^{u} & \ldots & \alpha_{1 n}^{u} \\
\alpha_{21}^{u} & \alpha_{22}^{u} & \ldots & \alpha_{2 n}^{u} \\
\ldots & \ldots & \vdots & \ldots \\
\alpha_{m 1}^{u} & \alpha_{m 2}^{u} & \ldots & \alpha_{m n}^{u}
\end{array}\right),
\end{gathered}
$$

where $\alpha_{i j}^{d}=\min _{1 \leq k \leq t}\left\{\alpha_{i j}^{(k)} \mid \alpha_{i j}^{(k)} \leq \alpha_{i j}^{+}\right\}$and $\alpha_{i j}^{u}=\max _{1 \leq k \leq t}\left\{\alpha_{i j}^{(k)} \mid \alpha_{i j}^{(k)} \geq \alpha_{i j}^{+}\right\}$are the intuitionsitic fuzzynegative ideal solutions (IFNISs).

The distances between $\alpha_{i j}^{(k)}=\left(\mu_{i j}^{(k)}, v_{i j}^{(k)}\right)$ and $\alpha_{i j}^{+}=\left(\mu_{i j}^{+}, v_{i j}^{+}\right), \alpha_{i j}^{d}=\left(\mu_{i j}^{d}, v_{i j}^{d}\right), \alpha_{i j}^{u}=\left(\mu_{i j}^{u}\right.$, $v_{i j}^{u}$ ) can be defined, respectively, as follows:

$$
\begin{aligned}
& d_{i j}^{+}=\frac{1}{2}\left(\left|\mu_{i j}^{(k)}-\mu_{i j}^{+}\right|+\left|v_{i j}^{(k)}-v_{i j}^{+}\right|\right) ; \\
& d_{i j}^{d}=\frac{1}{2}\left(\left|\mu_{i j}^{(k)}-\mu_{i j}^{d}\right|+\left|v_{i j}^{(k)}-v_{i j}^{d}\right|\right) ; \\
& d_{i j}^{u}=\frac{1}{2}\left(\left|\mu_{i j}^{(k)}-\mu_{i j}^{u}\right|+\left|v_{i j}^{(k)}-v_{i j}^{u}\right|\right) .
\end{aligned}
$$

The closeness coefficient of $\alpha_{i j}^{(k)}$ is determined by:

$$
c_{i j}^{(k)}=\frac{d_{i j}^{u}+d_{i j}^{d}}{d_{i j}^{u}+d_{i j}^{d}+d_{i j}^{+}}, i=1,2, \ldots, m, j=1,2, \ldots, n, k=1,2, \ldots, t,
$$

and the weight of the decision maker $E_{k}$ for the alternative $A_{i}$ with respect to the attribute $B_{j}$ can be determined as:

$$
w_{i j}^{(k)}=\frac{c_{i j}^{(k)}}{\sum_{k=1}^{t} c_{i j}^{(k)}}, i=1,2, \ldots, m, j=1,2, \ldots, n, k=1,2, \ldots, t,
$$

where $w_{i j}^{(k)} \geq 0, \sum_{k=1}^{t} w_{i j}^{(k)}=1$. The new weights have the characteristic that it is large if the evaluation value is close to the IFPIS, and it is small if the evaluation value is close to the IFNISs.

After obtaining the above new weights, we can aggregate the intuitionistic fuzzy evaluation values $\alpha_{i j}^{(k)}(k=1,2, \ldots, t)$ given by different decision makers $E_{k}(k=1,2, \ldots, t)$ into a collective one, $\alpha_{i j}$, by making use of the intuitionistic fuzzy weighted averaging (IFWA) operator:

$$
\alpha_{i j}=w_{i j}^{(1)} \alpha_{i j}^{(1)}+w_{i j}^{(2)} \alpha_{i j}^{(2)}+\ldots+w_{i j}^{(t)} \alpha_{i j}^{(t)} .
$$


Therefore, we can obtain the intuitionistic fuzzy collective decision matrix $D$ as:

$$
D=\left(\alpha_{i j}\right)_{m \times n}=\left(\begin{array}{cccc}
\alpha_{11} & \alpha_{12} & \ldots & \alpha_{1 n} \\
\alpha_{21} & \alpha_{22} & \ldots & \alpha_{2 n} \\
\ldots & \ldots & \vdots & \ldots \\
\alpha_{m 1} & \alpha_{m 2} & \ldots & \alpha_{m n}
\end{array}\right) .
$$

With the above preparation, we can now present our new MAGDM algorithm according to different situations about the attribute weight information. If the attribute weight vector is known exactly, the TOPSIS approach in intuitionistic fuzzy setting can be used to rank alternatives directly. The attribute weights should be determined firstly if they are known partly or unknown completely. In the decision making process, there are situations that the attribute weight information is not known exactly, but only part of which can be obtained. Generally, the partly known attribute weight information can be expressed as some subset of the following relations:

1) A weak ranking: $\left\{w_{i} \geq w_{j}\right\}, i \neq j$;

2) A strict ranking: $\left\{w_{i}-w_{j} \geq \varepsilon_{i}(>0)\right\}, i \neq j$;

3) A ranking with multiples: $\left\{w_{i} \geq \alpha_{i} w_{j}\right\}, 0 \leq \alpha_{i} \leq 1, i \neq j$;

4) An interval form : $\left\{\beta_{j} \leq w_{j} \leq \beta_{j}+\varepsilon_{j}\right\}, 0 \leq \beta_{j} \leq \beta_{j}+\varepsilon_{j} \leq 1$;

5) A ranking of differences : $\left\{w_{i}-w_{j} \geq w_{k}-w_{l}\right\}$, for $i \neq j \neq k \neq l$.

We denote the attribute weight information set as $H$. According to information theory, the attribute whose evaluation values are close to the positive ideal evaluation value and far from the negative ideal evaluation values at the same time should have a large weight, otherwise it should have a small weight. Basing on this principle, we calculate the closeness coefficient $c_{i j}$ of each collective evaluation value $\alpha_{i j}$ according to its distances to the positive ideal value $\alpha_{j}^{+}=(1,0)$ and the negative ideal value $\alpha_{j}^{-}=(0,1)$ as follows:

$$
c_{i j}=\frac{d\left(\alpha_{i j}, \alpha_{j}^{-}\right)}{d\left(\alpha_{i j}, \alpha_{j}^{+}\right)+d\left(\alpha_{i j}, \alpha_{j}^{-}\right)}, i=1,2, \ldots, m, j=1,2, \ldots, n .
$$

Then the weighted closeness coefficient is calculated as:

$$
c_{i}=\sum_{j=1}^{n} c_{i j} w_{j}, i=1,2, \ldots, m \text {. }
$$

A reasonable weight vector $W=\left(w_{1}, w_{2}, \ldots, w_{n}\right)$ should make the closeness coefficient as large as possible, thus we set up the following multiple objective programming model:

$$
\begin{aligned}
\max & \left\{\sum_{j=1}^{n} c_{1 j} w_{j}, \sum_{j=1}^{n} c_{2 j} w_{j}, \ldots, \sum_{j=1}^{n} c_{m j} w_{j},\right\} \\
\text { s.t. } \quad & W \in H \\
& w_{j} \geq 0, j=1,2, \ldots, n, \\
& w_{1}+w_{2}+\ldots+w_{n}=1 .
\end{aligned}
$$


Since all the objectives are equal important, the above multiple objective programming model can be transformed into the following single objective programming model by using the equally weighted summation method (French et al. 1983):

$$
\begin{aligned}
(\mathrm{M}-2) \max & \sum_{i=1}^{m} \sum_{j=1}^{n} c_{i j} w_{j} \\
\text { s.t. } & W \in H, \\
& w_{j} \geq 0, j=1,2, \ldots, n, \\
& w_{1}+w_{2}+\ldots+w_{n}=1 .
\end{aligned}
$$

In the above model, only the attribute weights $w_{j}(j=1,2, \ldots, n)$ are unknown, hence it is a linear programming problem, which can be solved by many algorithms such as the interior point algorithm, the simplex method, etc.

In some cases, the attribute weight information is unknown completely. Then we can determine attribute weights according to the principle that the attribute whose collective evaluation values are close to the intuitionistic fuzzy positive ideal value and far from the intuitionsitic fuzzy negative ideal values at the same time should have a large weight. In order to do this, the attribute weights can be determined as:

$$
w_{j}=\frac{c_{j}}{\sum_{j=1}^{n} c_{j}}=\frac{\sum_{i=1}^{m} c_{i j}}{\sum_{j=1}^{n} \sum_{i=1}^{m} c_{i j}}, j=1, \ldots, n,
$$

where $c_{i j}$ is determined by Eq. (15) and $w_{j} \geq 0, \sum_{j=1}^{n} w_{j}=1$.

In the following, we give the new algorithm based on the new attribute weight assignment method and TOPSIS method. The concrete steps are as follows:

\section{Algorithm}

Step 1. Decision makers evaluate alternatives with respect to the attributes to obtain the decision matrices $D^{(k)}=\left(\alpha_{i j}^{(k)}\right)_{m \times n}$, where $\alpha_{i j}^{(k)}$ is an IFV.

Step 2. Determine the positive ideal decision matrix $D^{+}=\left(\alpha_{i j}^{+}\right)_{m \times n}$ and negative ideal decision matrices $D^{d}=\left(\alpha_{i j}^{d}\right)_{m \times n}, D^{u}=\left(\alpha_{i j}^{u}\right)_{m \times n}$ by using Eqs (5), (6) and (7), respectively.

Step 3. Calculate the closeness coefficient of each evaluation value according to Eqs (8), (9), (10) and (11), respectively, and evaluation values' weights by using Eq. (12). Then the collective decision matrix $D=\left(\alpha_{i j}\right)_{m \times n}$ can be determined by using the IFWA operator as Eq. (13).

Step 4. If the attribute weight vector is known exactly, go to Step 5 directly. Model (M-2) can be used to determine attribute weights if they are known partly. For the case of completely unknown weight information, Eq. (17) can be used to calculate the attribute weight vector.

Step 5. Calculate the weighted decision matrix as $D^{\prime}=\left(\alpha_{i j}^{\prime}\right)_{m \times n}$, where $\alpha_{i j}^{\prime}=w_{j} \alpha_{i j}$ and $W=\left(w_{1}, w_{2}, \ldots, w_{n}\right)$ is the attribute weight vector. 
Step 6. Let $\alpha_{j}^{+}=(1,0)(j=1,2, \ldots, n)$ be $n$ largest IFVs, then the intuitionistic fuzzy positive ideal evaluation value $A^{+}$is defined as:

$$
A^{+}=\left(\alpha_{1}^{+}, \alpha_{2}^{+}, \ldots, \alpha_{n}^{+}\right) .
$$

Let $\alpha_{j}^{-}=(0,1)(j=1,2, \ldots, n)$ be $n$ smallest IFVs, then the intuitionistic fuzzy negative ideal evaluation value $A^{-}$is defined as:

$$
A^{-}=\left(\alpha_{1}^{-}, \alpha_{2}^{-}, \ldots, \alpha_{n}^{-}\right) .
$$

Calculate the distance of each alternative's collective evaluation value to $A^{+}$and $A^{-}$, respectively, by the following equations:

$$
\begin{aligned}
& d_{i}^{+}=\sum_{j=1}^{n} d\left(\alpha_{i j}^{\prime}, \alpha_{j}^{+}\right), i=1,2, \ldots, m \\
& d_{i}^{-}=\sum_{j=1}^{n} d\left(\alpha_{i j}^{\prime}, \alpha_{j}^{-}\right), i=1,2, \ldots, m .
\end{aligned}
$$

Step 7. Calculate each alternative's closeness coefficient as follows:

$$
c_{i}=\frac{d_{i}^{-}}{d_{i}^{-}+d_{i}^{+}}, i=1,2, \ldots, m .
$$

Step 8. Rank the alternatives' closeness coefficients by the value of $c_{i}(i=1,2, \ldots, m)$ in descending order and rank the alternatives accordingly.

Now, we have essentially developed three algorithms according to different situations about the attribute weight information: the attribute weight information is known completely, partly known and unknown completely. In the process of aggregating different decision matrices, the weights are determined from the evaluation values, and different experts have different weights for different attributes and alternatives, which is more reasonable in practical decision process, especially for the large-scale decision making problem where many decision makers are involved to select the optimal alternative among many candidates according to many attributes. For the real decision making problem, the decision maker can select the corresponding algorithm according to concrete situation of the problem's attribute information. In order to illustrate the efficiency and practical advantages of the proposed algorithm, we apply it to two decision making problems in the next section.

\section{Numerical illustration}

Two examples are used to demonstrate the practicality and efficiency of our new method.

Example 1. This example is adapted from Ngwenyama and Bryson (1999).

The Midwest American Manufacturing Corporation has steered a committee including the Chief Executive Officer, the Chief Information Officer, and the Chief Operating Officer to evaluate and rank eight information technology improvement projects $A_{i}(i=1,2, \ldots, 8)$ proposed by area managers: $A_{1}$ - quality management information, $A_{2}$ - inventory control, $A_{3}$ - customer order tracking, $A_{4}$ - material purchasing management, $A_{5}$ - fleet manage- 
ment, $A_{6}$ - design change management, $A_{7}$ - employee skills tracking and $A_{8}$-budget analysis. The committee concerns each project's potential contribution to the firm's strategic goal of gaining the competitive advantage in the industry. Four decision makers $d_{i}(i=1,2, \ldots, 4)$ are selected by the committee to evaluate the alternatives with respect to the following six attributes: $B_{1}$ - productivity, $B_{2}$ - technological innovation capability, $B_{3}$ - marketing capability, $B_{4}$ - differentiation, $B_{5}$ - management, and $B_{6}$ - risk avoidance.

If the attribute weight vector is known exactly as $W=(0.2,0.12,0.1,0.1,0.35,0.13)$, the new Algorithm can be used to rank the alternatives. The concrete steps are as follows:

Step 1. Decision makers evaluate alternatives with respect to the attributes to get decision matrices $D^{(k)}=\left(\alpha_{i j}^{(k)}\right)=\left(\mu_{i j}^{(k)}, v_{i j}^{(k)}\right), k=1,2,3,4$, which are shown in Tables 1-4.

Step 2. Determine the intuitionistic fuzzy positive ideal decision matrix $D^{+}$as Table 5 and the intuitionistic fuzzy negative ideal decision matrices $D^{u}$ and $D^{d}$ as those in Table 6 and Table 7, respectively.

Step 3. For each decision maker $d_{k}, k=1, \ldots, 4$, calculate the distances of each evaluation value $\alpha_{i j}^{(k)}$ to the positive ideal evaluation value $\alpha_{i j}^{+}$and negative ideal evaluation values $\alpha_{i j}^{u}, \alpha_{i j}^{d}$. Then calculate the relative closeness coefficient by Eq. (11) and the weight $w_{i j}^{(k)}$ of the evaluation value by Eq. (12). Aggregate evaluation values $\alpha_{i j}^{(1)}, \alpha_{i j}^{(2)}, \alpha_{i j}^{(3)}, \alpha_{i j}^{(4)}$ given by four decision makers into a collective one $\alpha_{i j}$ by using the IFWA operator. The resulting decision matrix is formed as Table 8.

Table 1. Intuitionistic fuzzy decision matrix $D^{(1)}$

\begin{tabular}{ccccccc}
\hline & $B_{1}$ & $B_{2}$ & $B_{3}$ & $B_{4}$ & $B_{5}$ & $B_{6}$ \\
\hline$A_{1}$ & $(0.4,0.5)$ & $(0.6,0.2)$ & $(0.8,0.1)$ & $(0.3,0.4)$ & $(0.5,0.3)$ & $(0.2,0.5)$ \\
\hline$A_{2}$ & $(0.5,0.3)$ & $(0.3,0.5)$ & $(0.4,0.4)$ & $(0.7,0.2)$ & $(0.6,0.4)$ & $(0.8,0.2)$ \\
\hline$A_{3}$ & $(0.5,0.2)$ & $(0.4,0.5)$ & $(0.3,0.6)$ & $(0.6,0.3)$ & $(0.5,0.5)$ & $(0.6,0.1)$ \\
\hline$A_{4}$ & $(0.7,0.1)$ & $(0.3,0.3)$ & $(0.6,0.2)$ & $(0.4,0.3)$ & $(0.3,0.6)$ & $(0.5,0.4)$ \\
\hline$A_{5}$ & $(0.3,0.4)$ & $(0.6,0.2)$ & $(0.5,0.4)$ & $(0.8,0.2)$ & $(0.4,0.3)$ & $(0.5,0.2)$ \\
\hline$A_{6}$ & $(0.5,0.4)$ & $(0.7,0.3)$ & $(0.2,0.6)$ & $(0.5,0.3)$ & $(0.6,0.2)$ & $(0.3,0.5)$ \\
\hline$A_{7}$ & $(0.2,0.6)$ & $(0.5,0.4)$ & $(0.6,0.3)$ & $(0.5,0.2)$ & $(0.3,0.4)$ & $(0.7,0.3)$ \\
\hline$A_{8}$ & $(0.5,0.5)$ & $(0.3,0.4)$ & $(0.5,0.3)$ & $(0.6,0.2)$ & $(0.9,0.1)$ & $(0.2,0.4)$ \\
\hline
\end{tabular}

Table 2. Intuitionistic fuzzy decision matrix $D^{(2)}$

\begin{tabular}{ccccccc}
\hline & $B_{1}$ & $B_{2}$ & $B_{3}$ & $B_{4}$ & $B_{5}$ & $B_{6}$ \\
\hline$A_{1}$ & $(0.5,0.5)$ & $(0.7,0.2)$ & $(0.6,0.3)$ & $(0.4,0.4)$ & $(0.5,0.4)$ & $(0.3,0.5)$ \\
\hline$A_{2}$ & $(0.3,0.2)$ & $(0.3,0.4)$ & $(0.5,0.4)$ & $(0.7,0.3)$ & $(0.6,0.3)$ & $(0.8,0.1)$ \\
\hline$A_{3}$ & $(0.5,0.3)$ & $(0.4,0.4)$ & $(0.3,0.5)$ & $(0.6,0.2)$ & $(0.5,0.4)$ & $(0.6,0.2)$ \\
\hline$A_{4}$ & $(0.8,0.2)$ & $(0.5,0.3)$ & $(0.6,0.3)$ & $(0.4,0.2)$ & $(0.2,0.5)$ & $(0.3,0.6)$ \\
\hline$A_{5}$ & $(0.2,0.4)$ & $(0.6,0.3)$ & $(0.4,0.5)$ & $(0.7,0.2)$ & $(0.5,0.2)$ & $(0.4,0.3)$ \\
\hline$A_{6}$ & $(0.4,0.5)$ & $(0.8,0.2)$ & $(0.3,0.5)$ & $(0.4,0.3)$ & $(0.6,0.1)$ & $(0.5,0.4)$ \\
\hline$A_{7}$ & $(0.3,0.5)$ & $(0.5,0.2)$ & $(0.6,0.1)$ & $(0.3,0.5)$ & $(0.3,0.5)$ & $(0.6,0.3)$ \\
\hline$A_{8}$ & $(0.5,0.3)$ & $(0.2,0.5)$ & $(0.5,0.4)$ & $(0.8,0.2)$ & $(0.8,0.2)$ & $(0.3,0.4)$ \\
\hline
\end{tabular}


Table 3. Intuitionistic fuzzy decision matrix $D^{(3)}$

\begin{tabular}{ccccccc}
\hline & $B_{1}$ & $B_{2}$ & $B_{3}$ & $B_{4}$ & $B_{5}$ & $B_{6}$ \\
\hline$A_{1}$ & $(0.5,0.4)$ & $(0.7,0.3)$ & $(0.7,0.2)$ & $(0.3,0.3)$ & $(0.4,0.5)$ & $(0.3,0.5)$ \\
\hline$A_{2}$ & $(0.3,0.4)$ & $(0.2,0.6)$ & $(0.6,0.3)$ & $(0.8,0.2)$ & $(0.5,0.3)$ & $(0.7,0.2)$ \\
\hline$A_{3}$ & $(0.4,0.3)$ & $(0.5,0.4)$ & $(0.2,0.5)$ & $(0.6,0.1)$ & $(0.5,0.2)$ & $(0.5,0.3)$ \\
\hline$A_{4}$ & $(0.7,0.2)$ & $(0.4,0.4)$ & $(0.7,0.3)$ & $(0.3,0.5)$ & $(0.3,0.4)$ & $(0.4,0.5)$ \\
\hline$A_{5}$ & $(0.3,0.5)$ & $(0.7,0.3)$ & $(0.3,0.4)$ & $(0.8,0.1)$ & $(0.4,0.2)$ & $(0.5,0.2)$ \\
\hline$A_{6}$ & $(0.4,0.4)$ & $(0.9,0.1)$ & $(0.3,0.6)$ & $(0.5,0.2)$ & $(0.6,0.3)$ & $(0.4,0.6)$ \\
\hline$A_{7}$ & $(0.3,0.5)$ & $(0.6,0.3)$ & $(0.7,0.2)$ & $(0.4,0.3)$ & $(0.2,0.5)$ & $(0.8,0.1)$ \\
\hline$A_{8}$ & $(0.5,0.4)$ & $(0.2,0.6)$ & $(0.6,0.3)$ & $(0.7,0.2)$ & $(0.8,0.1)$ & $(0.2,0.5)$ \\
\hline
\end{tabular}

Table 4. Intuitionistic fuzzy decision matrix $D^{(4)}$

\begin{tabular}{ccccccc}
\hline & $B_{1}$ & $B_{2}$ & $B_{3}$ & $B_{4}$ & $B_{5}$ & $B_{6}$ \\
\hline$A_{1}$ & $(0.6,0.3)$ & $(0.7,0.1)$ & $(0.7,0.3)$ & $(0.3,0.5)$ & $(0.6,0.3)$ & $(0.3,0.6)$ \\
\hline$A_{2}$ & $(0.7,0.2)$ & $(0.4,0.4)$ & $(0.5,0.3)$ & $(0.8,0.1)$ & $(0.6,0.2)$ & $(0.7,0.3)$ \\
\hline$A_{3}$ & $(0.6,0.3)$ & $(0.4,0.3)$ & $(0.3,0.4)$ & $(0.7,0.3)$ & $(0.5,0.2)$ & $(0.6,0.3)$ \\
\hline$A_{4}$ & $(0.7,0.3)$ & $(0.5,0.4)$ & $(0.7,0.2)$ & $(0.5,0.2)$ & $(0.2,0.4)$ & $(0.3,0.5)$ \\
\hline$A_{5}$ & $(0.4,0.5)$ & $(0.7,0.2)$ & $(0.3,0.5)$ & $(0.6,0.3)$ & $(0.5,0.3)$ & $(0.4,0.2)$ \\
\hline$A_{6}$ & $(0.6,0.4)$ & $(0.8,0.1)$ & $(0.2,0.5)$ & $(0.5,0.4)$ & $(0.7,0.2)$ & $(0.4,0.6)$ \\
\hline$A_{7}$ & $(0.2,0.5)$ & $(0.6,0.2)$ & $(0.7,0.3)$ & $(0.6,0.4)$ & $(0.2,0.4)$ & $(0.6,0.2)$ \\
\hline$A_{8}$ & $(0.6,0.2)$ & $(0.3,0.5)$ & $(0.6,0.2)$ & $(0.8,0.2)$ & $(0.7,0.2)$ & $(0.3,0.6)$ \\
\hline & & & & & &
\end{tabular}

Table 5. Intuitionistic fuzzy positive ideal decision matrix $D^{+}$

\begin{tabular}{ccccccc}
\hline & $B_{1}$ & $B_{2}$ & $B_{3}$ & $B_{4}$ & $B_{5}$ & $B_{6}$ \\
\hline$A_{1}$ & $(0.5051,0.4162)$ & $(0.6776,0.1861)$ & $(0.7087,0.2060)$ & $(0.3265,0.3936)$ & $(0.5051,0.3663)$ & $(0.2762,0.5233)$ \\
\hline$A_{2}$ & $(0.3565,0.2632)$ & $(0.3036,0.4681)$ & $(0.5051,0.3464)$ & $(0.7551,0.1861)$ & $(0.6064,0.2913)$ & $(0.7551,0.1861)$ \\
\hline$A_{3}$ & $(0.5051,0.2711)$ & $(0.4267,0.3936)$ & $(0.2762,0.4949)$ & $(0.6278,0.2060)$ & $(0.5000,0.2991)$ & $(0.5771,0.2060)$ \\
\hline$A_{4}$ & $(0.7289,0.1861)$ & $(0.4308,0.3464)$ & $(0.6536,0.2449)$ & $(0.4042,0.2783)$ & $(0.2517,0.4681)$ & $(0.3808,0.4949)$ \\
\hline$A_{5}$ & $(0.3036,0.4472)$ & $(0.6536,0.2449)$ & $(0.3808,0.4472)$ & $(0.7368,0.1861)$ & $(0.4523,0.2449)$ & $(0.4523,0.2213)$ \\
\hline$A_{6}$ & $(0.4820,0.4229)$ & $(0.8139,0.1565)$ & $(0.2517,0.5477)$ & $(0.4767,0.2613)$ & $(0.6278,0.1861)$ & $(0.4042,0.5180)$ \\
\hline$A_{7}$ & $(0.2517,0.4949)$ & $(0.5528,0.2632)$ & $(0.6536,0.2060)$ & $(0.4820,0.3130)$ & $(0.2517,0.4472)$ & $(0.6870,0.2060)$ \\
\hline$A_{8}$ & $(0.5271,0.3310)$ & $(0.2517,0.4949)$ & $(0.5528,0.2913)$ & $(0.6870,0.2213)$ & $(0.7940,0.1565)$ & $(0.2517,0.4681)$ \\
\hline
\end{tabular}

Table 6. Intuitionistic fuzzy negative ideal decision matrix $D^{u}$

\begin{tabular}{ccccccc}
\hline & $B_{1}$ & $B_{2}$ & $B_{3}$ & $B_{4}$ & $B_{5}$ & $B_{6}$ \\
\hline$A_{1}$ & $(0.6,0.3)$ & $(0.7,0.1)$ & $(0.8,0.1)$ & $(0.4,0.4)$ & $(0.6,0.3)$ & $(0.3,0.5)$ \\
\hline$A_{2}$ & $(0.5,0.3)$ & $(0.4,0.4)$ & $(0.6,0.3)$ & $(0.8,0.1)$ & $(0.6,0.2)$ & $(0.8,0.1)$ \\
\hline$A_{3}$ & $(0.6,0.3)$ & $(0.5,0.4)$ & $(0.3,0.4)$ & $(0.6,0.1)$ & $(0.5,0.2)$ & $(0.6,0.1)$ \\
\hline$A_{4}$ & $(0.8,0.2)$ & $(0.5,0.3)$ & $(0.7,0.2)$ & $(0.5,0.2)$ & $(0.3,0.4)$ & $(0.5,0.4)$ \\
\hline$A_{5}$ & $(0.4,0.5)$ & $(0.7,0.2)$ & $(0.5,0.4)$ & $(0.8,0.1)$ & $(0.5,0.2)$ & $(0.5,0.2)$ \\
\hline$A_{6}$ & $(0.6,0.4)$ & $(0.9,0.1)$ & $(0.3,0.5)$ & $(0.5,0.2)$ & $(0.9,0.1)$ & $(0.5,0.4)$ \\
\hline$A_{7}$ & $(0.3,0.4)$ & $(0.6,0.2)$ & $(0.7,0.2)$ & $(0.5,0.2)$ & $(0.3,0.4)$ & $(0.8,0.1)$ \\
\hline$A_{8}$ & $(0.6,0.2)$ & $(0.3,0.4)$ & $(0.6,0.2)$ & $(0.8,0.2)$ & $(0.9,0.1)$ & $(0.3,0.4)$ \\
\hline & & & & & &
\end{tabular}


Table 7. Intuitionistic fuzzy negative ideal decision matrix $D^{d}$

\begin{tabular}{ccccccc}
\hline & $B_{1}$ & $B_{2}$ & $B_{3}$ & $B_{4}$ & $B_{5}$ & $B_{6}$ \\
\hline$A_{1}$ & $(0.4,0.5)$ & $(0.6,0.2)$ & $(0.6,0.3)$ & $(0.3,0.5)$ & $(0.4,0.5)$ & $(0.2,0.5)$ \\
\hline$A_{2}$ & $(0.3,0.4)$ & $(0.2,0.6)$ & $(0.4,0.4)$ & $(0.7,0.3)$ & $(0.5,0.3)$ & $(0.7,0.3)$ \\
\hline$A_{3}$ & $(0.4,0.3)$ & $(0.4,0.5)$ & $(0.2,0.5)$ & $(0.6,0.3)$ & $(0.5,0.5)$ & $(0.5,0.3)$ \\
\hline$A_{4}$ & $(0.7,0.3)$ & $(0.3,0.3)$ & $(0.6,0.3)$ & $(0.3,0.5)$ & $(0.2,0.5)$ & $(0.3,0.6)$ \\
\hline$A_{5}$ & $(0.2,0.4)$ & $(0.6,0.3)$ & $(0.3,0.5)$ & $(0.6,0.3)$ & $(0.4,0.3)$ & $(0.4,0.3)$ \\
\hline$A_{6}$ & $(0.4,0.5)$ & $(0.7,0.3)$ & $(0.2,0.6)$ & $(0.4,0.3)$ & $(0.6,0.3)$ & $(0.3,0.5)$ \\
\hline$A_{7}$ & $(0.2,0.6)$ & $(0.5,0.4)$ & $(0.6,0.3)$ & $(0.4,0.4)$ & $(0.2,0.5)$ & $(0.6,0.3)$ \\
\hline$A_{8}$ & $(0.5,0.5)$ & $(0.2,0.6)$ & $(0.5,0.4)$ & $(0.6,0.3)$ & $(0.7,0.2)$ & $(0.2,0.5)$ \\
\hline
\end{tabular}

Table 8. Intuitionistic fuzzy collective decision matrix $D$

\begin{tabular}{ccccccc}
\hline & $B_{1}$ & $B_{2}$ & $B_{3}$ & $B_{4}$ & $B_{5}$ & $B_{6}$ \\
\hline$A_{1}$ & $(0.5036,0.4193)$ & $(0.3791,0.1902)$ & $(0.7077,0.2084)$ & $(0.3257,0.3883)$ & $(0.5072,0.3620)$ & $(0.2818,0.5269)$ \\
\hline$A_{2}$ & $(0.3538,0.2587)$ & $(0.3057,0.4639)$ & $(0.5053,0.3457)$ & $(0.7564,0.1856)$ & $(0.6067,0.2895)$ & $(0.7564,0.1856)$ \\
\hline$A_{3}$ & $(0.5049,0.2669)$ & $(0.4260,0.3883)$ & $(0.2773,0.4996)$ & $(0.6282,0.2090)$ & $(0.5000,0.2908)$ & $(0.5804,0.2044)$ \\
\hline$A_{4}$ & $(0.7282,0.1801)$ & $(0.4366,0.3542)$ & $(0.6542,0.2441)$ & $(0.4079,0.2694)$ & $(0.2515,0.4716)$ & $(0.3776,0.4966)$ \\
\hline$A_{5}$ & $(0.3032,0.4470)$ & $(0.6542,0.2441)$ & $(0.3791,0.4499)$ & $(0.7416,0.1840)$ & $(0.4527,0.2441)$ & $(0.4549,0.2181)$ \\
\hline$A_{6}$ & $(0.4824,0.4202)$ & $(0.8165,0.1515)$ & $(0.2519,0.5473)$ & $(0.4779,0.2958)$ & $(0.6281,0.1858)$ & $(0.3994,0.5310)$ \\
\hline$A_{7}$ & $(0.2521,0.4949)$ & $(0.5559,0.2595)$ & $(0.6553,0.1982)$ & $(0.4824,0.3115)$ & $(0.2519,0.4468)$ & $(0.6822,0.2106)$ \\
\hline$A_{8}$ & $(0.5239,0.3321)$ & $(0.2521,0.4949)$ & $(0.5536,0.2911)$ & $(0.6880,0.2184)$ & $(0.7962,0.1556)$ & $(0.2515,0.4716)$ \\
\hline
\end{tabular}

Table 9. Intuitionistic fuzzy weighted decision matrix $D^{\prime}$

\begin{tabular}{ccccccc}
\hline & $B_{1}$ & $B_{2}$ & $B_{3}$ & $B_{4}$ & $B_{5}$ & $B_{6}$ \\
\hline$A_{1}$ & $(0.1307,0.8404)$ & $(0.1275,0.8194)$ & $(0.1157,0.8549)$ & $(0.0386,0.9097)$ & $(0.2194,0.7007)$ & $(0.0421,0.9201)$ \\
\hline$A_{2}$ & $(0.0836,0.7630)$ & $(0.0428,0.9120)$ & $(0.0680,0.8992)$ & $(0.1317,0.8450)$ & $(0.2786,0.6480)$ & $(0.1677,0.8034)$ \\
\hline$A_{3}$ & $(0.1312,0.7678)$ & $(0.0644,0.8927)$ & $(0.0319,0.9330)$ & $(0.0942,0.8551)$ & $(0.2154,0.6490)$ & $(0.1068,0.8135)$ \\
\hline$A_{4}$ & $(0.2293,0.7098)$ & $(0.0665,0.8829)$ & $(0.1007,0.8685)$ & $(0.0511,0.8711)$ & $(0.0964,0.7687)$ & $(0.0598,0.9130)$ \\
\hline$A_{5}$ & $(0.0697,0.8513)$ & $(0.1196,0.8443)$ & $(0.0465,0.9232)$ & $(0.1266,0.8443)$ & $(0.1902,0.6105)$ & $(0.0759,0.8204)$ \\
\hline$A_{6}$ & $(0.1234,0.8408)$ & $(0.1841,0.7973)$ & $(0.0286,0.9415)$ & $(0.0629,0.8853)$ & $(0.2926,0.5548)$ & $(0.0641,0.9210)$ \\
\hline$A_{7}$ & $(0.0564,0.8688)$ & $(0.0928,0.8506)$ & $(0.1010,0.8506)$ & $(0.0637,0.8899)$ & $(0.0966,0.7543)$ & $(0.1384,0.8167)$ \\
\hline$A_{8}$ & $(0.1380,0.8021)$ & $(0.0343,0.9190)$ & $(0.0775,0.8839)$ & $(0.1099,0.8589)$ & $(0.4269,0.5214)$ & $(0.0370,0.9069)$ \\
\hline
\end{tabular}

Steps 4 and 5. With the known attribute weight vector $W=(0.2,0.12,0.1,0.1,0.35,0.13)$, the weighted decision matrix $D^{\prime}=\left(\alpha_{i j}^{\prime}\right)_{8 \times 6}$ is calculated and the results are shown in Table 9, where $\alpha_{i j}^{\prime}=w_{j} \alpha_{i j}$.

Step 6. Calculate the distances of alternatives' evaluation values to the intuitionistic fuzzy positive ideal evaluation value $A^{+}$and the intuitionistic fuzzy negative ideal evaluation value $A^{-}$, which give us:

$$
d_{1}^{+}=5.1856, d_{2}^{+}=5.0491, d_{3}^{+}=5.1336, d_{4}^{+}=5.2080, d_{5}^{+}=5.1327, d_{6}^{+}=5.0925, d_{7}^{+}=
$$


$5.2408, d_{8}^{+}=5.0344, d_{1}^{-}=0.8144, d_{2}^{-}=0.9509, d_{3}^{-}=0.8664, d_{4}^{-}=0.7920, d_{5}^{-}=0.8673$, $d_{6}^{-}=0.0975, d_{7}^{-}=0.7592, d_{8}^{-}=0.9656$.

Step 7. The relative closeness coefficients are then determined as:

$c_{1}=0.1357, c_{2}=0.1585, c_{3}=0.1444, c_{4}=0.1320, c_{5}=0.1445, c_{6}=0.1512, c_{7}=0.1265$, $c_{8}=0.1609$.

Step 8. Rank alternatives' relative coefficients to get:

$c_{8}>c_{2}>c_{6}>c_{5}>c_{3}>c_{1}>c_{4}>c_{7}$.

The alternatives can thus be ranked accordingly as:

$A_{8}>A_{2}>A_{6}>A_{5}>A_{3}>A_{1}>A_{4}>A_{7}$,

the optimal alternative is $A_{8}$.

In the above example, the weights of different decision makers are different for different evaluation values. For example, the weights of $\alpha_{11}^{(1)}=(0.4,0.5), \alpha_{11}^{(2)}=(0.5,0.5)$, $\alpha_{11}^{(3)}=(0.5,0.4), \alpha_{11}^{(4)}=(0.6,0.3)$ can be computed as $w_{11}^{(1)}=0.2190, w_{11}^{(2)}=0.2638, \quad w_{11}^{(3)}=$ 0.3062 , and $w_{11}^{(4)}=0.2110$, respectively, and the weights of $\alpha_{31}^{(1)}=(0.5,0.2), \alpha_{31}^{(2)}=(0.5,0.3)$, $\alpha_{31}^{(3)}=(0.4,0.3)$ and $\alpha_{31}^{(4)}=(0.6,0.3)$ can be computed as $w_{31}^{(1)}=0.2886, \quad w_{31}^{(2)}=0.2936$, $w_{31}^{(3)}=0.2057$ and $w_{31}^{(4)}=0.2121$, respectively. The positive ideal evaluation value of $\alpha_{11}^{(1)}, \alpha_{11}^{(2)}, \alpha_{11}^{(3)}, \alpha_{11}^{(4)}$ is $\alpha^{+}=(0.5000,0.4250)$ and the corresponding negative ideal evaluation values are $\alpha_{11}^{u}=(0.6,0.3), \alpha_{11}^{d}=(0.4,0.5)$. Since the evaluation value $\alpha_{11}^{(3)}$ is the one closest to $\alpha_{11}^{(1)}$ and farthest from $\alpha_{11}^{u}$ and $\alpha_{11}^{d}, \alpha_{11}^{(3)}$ has a large weight. The evaluation value $\alpha_{11}^{(4)}$ is the one farthest from $\alpha_{11}^{+}$and closest to $\alpha_{11}^{u}$, hence it has a small weight. While for evaluation values $\alpha_{31}^{(1)}, \alpha_{31}^{(2)}, \alpha_{31}^{(3)}, \alpha_{31}^{(4)}$, the positive ideal evaluation value and negative ideal evaluation values are $\alpha_{31}^{+}=(0.5000,0.2750), \alpha_{31}^{u}=(0.6,0.3)$ and $\alpha_{31}^{d}=(0.4,0.3)$, respectively. The evaluation value $\alpha_{31}^{(2)}$ is the one closest to $\alpha_{31}^{+}$and farthest from $\alpha_{31}^{u}$ and $\alpha_{31}^{d}$, hence it has a large weight and evaluation values $\alpha_{31}^{(3)}$ and $\alpha_{31}^{(4)}$ are the ones farthest from $\alpha_{31}^{+}$ and closest to $\alpha_{31}^{d}$, hence they have small weights. From the above results, we can see that different evaluation values are assigned different weights. As pointed out in Section 2, the weights determined by the proposed method can reduce the influence of unduly high or low evaluation values on the ranking result.

In order to illustrate the advantages of the proposed method, we compare it with the method that the weights of experts are determined beforehand, in which all the weights of experts are the same for all the attributes. For example, the weights of experts are taken as $(0.20,0.25,0.15,0.40)$. Then the collective decision matrix $\tilde{D}$ can be determined as in Table 10. The attribute weight vector is known as $W=(0.2,0.12,0.1,0.1,0.35,0.13)$. By using the TOPSIS method, the alternatives' relative closeness coefficients are calculated as $c_{1}=0.1390, c_{2}=0.1617, c_{3}=0.1449, c_{4}=0.1318, c_{5}=0.1423, c_{6}=0.1529, \quad c_{7}=0.1258$, $c_{8}=0.1603$. The ranking of $c_{i}(i=1,2, \ldots, 8)$ is then $c_{2}>c_{8}>c_{6}>c_{3}>c_{5}>c_{1}>c_{4}>c_{7}$, and the ranking of the alternatives can be determined accordingly as $A_{2}>A_{8}>A_{6}>A_{3}>$ $A_{5}>A_{1}>A_{4}>A_{7}$. Now, the optimal alternative is $A_{2}$, which is different from the optimal alternative determined by our Algorithm. Here the weights of decision makers are the same for all the attributes. But in the real decision making process, decision problems have become very complicated and more knowledge is needed. Usually, experts may be familiar 
with some attributes but not familiar with other attributes, hence they may give reasonable evaluation values for some attributes and probably unreasonable evaluation values for other attributes. Compared with existing methods, the proposed algorithm can reduce the influence of unduly high or low evaluation values on the ranking results.

Table 10. Intuitionistic fuzzy weighted decision matrix $\tilde{D}$

\begin{tabular}{ccccccc}
\hline & $B_{1}$ & $B_{2}$ & $B_{3}$ & $B_{4}$ & $B_{5}$ & $B_{6}$ \\
\hline$A_{1}$ & $(0.5257,0.3642)$ & $(0.6822 .0 .1611)$ & $(0.7027,0.2266)$ & $(0.3265,0.4189)$ & $(0.5300,0.3480)$ & $(0.2811,0.5378)$ \\
\hline$A_{2}$ & $(0.3456,0.2407)$ & $(0.3285,0.4445)$ & $(0.4985,0.3415)$ & $(0.7600,0.1677)$ & $(0.6151,0.2702)$ & $(0.7500,0.1978)$ \\
\hline$A_{3}$ & $(0.5300,0.2733)$ & $(0.4162,0.3728)$ & $(0.2858,0.4743)$ & $(0.6435,0.2299)$ & $(0.5000,0.2857)$ & $(0.5864,0.2176)$ \\
\hline$A_{4}$ & $(0.7289,0.2048)$ & $(0.4504,0.3514)$ & $(0.6585,0.2352)$ & $(0.4292,0.2489)$ & $(0.2365,0.4587)$ & $(0.3605,0.50005)$ \\
\hline$A_{5}$ & $(0.3195,0.4522)$ & $(0.6585,0.2352)$ & $(0.3703,0.4624)$ & $(0.7079,0.2120)$ & $(0.4671,0.2551)$ & $(0.4371,0.2213)$ \\
\hline$A_{6}$ & $(0.5081,0.4229)$ & $(0.8045,0.1481)$ & $(0.2416,0.5329)$ & $(0.4767,0.3167)$ & $(0.6435,0.1787)$ & $(0.6597,0.2163)$ \\
\hline$A_{7}$ & $(0.2416,0.4904)$ & $(0.5577,0.2441)$ & $(0.6585,0.2145)$ & $(0.5081,0.3335)$ & $(0.2467,0.4373)$ & $(0.6597,0.2163)$ \\
\hline$A_{8}$ & $(0.5427,0.2950)$ & $(0.2616,0.4914)$ & $(0.5577,0.2714)$ & $(0.7097,0.2213)$ & $(0.7824,0.1845)$ & $(0.2665,0.4864)$ \\
\hline
\end{tabular}

If the attribute weight information is partly known as $H$ :

$$
\begin{aligned}
H= & \left\{0.10 \leq w_{1} \leq 0.20,0.20 \leq w_{2} \leq 0.30,0.15 \leq w_{3} \leq 0.25,\right. \\
& \left.0.10 \leq w_{4} \leq 0.25,0.12 \leq w_{5} \leq 0.28,0.10 \leq w_{1} \leq 0.20, w_{2} \leq 2 w_{4}\right\} .
\end{aligned}
$$

The attribute weights should be determined firstly and the following model is set up:

$(\mathrm{M}-3) \max 4.4092 w_{1}+4.4810 w_{2}+4.5911 w_{3}+5.2113 w_{4}+4.7638 w_{5}+4.4595 w_{6}$

s.t. $0.10 \leq w_{1} \leq 0.20,0.20 \leq w_{2} \leq 0.30,0.15 \leq w_{3} \leq 0.25,0.10 \leq w_{4} \leq 0.25$, $0.12 \leq w_{5} \leq 0.28,0.10 \leq w_{1} \leq 0.20, w_{2} \leq 2 w_{4}, w_{1}+w_{2}+\ldots+w_{6}=1$.

By solving the above linear programming problem, the attribute weight vector can be determined as $(0.10,0.28,0.15,0.25,0.12,0.10)$. The weighted matrix $D^{\prime \prime}$ can be calculated as that in Table 11. Calculate the distances of each alternative's weighted evaluation value to $A^{+}$and $A^{-}$to get $d_{1}^{+}=5.1158, d_{2}^{+}=5.0604, d_{3}^{+}=5.1474, d_{4}^{+}=5.1726, d_{6}^{+}=5.0587, d_{2}^{-}=0.9396$, $d_{3}^{-}=0.8526, d_{4}^{-}=0.8274, d_{5}^{-}=0.9679, d_{6}^{-}=0.9413, d_{7}^{-}=0.8806$ and $d_{8}^{-}=0.8798$. Then by using the TOPSIS method, the relative closeness coefficients can be determined as $c_{1}=0.1474, c_{2}=0.9396, c_{3}=0.8526, c_{4}=0.1379, c_{5}=0.1613, c_{6}=0.1569, c_{7}=$ 0.1468 and $c_{8}=0.1466$. Rank the relative closeness coefficients to give $c_{5}>c_{6}>c_{2}>c_{1}>$ $c_{7}>c_{8}>c_{3}>c_{4}$. The ranking of the alternatives can be determined accordingly as $A_{5}>A_{6}>A_{2}>A_{1}>A_{7}>A_{8}>A_{3}>A_{4}$. The optimal alternative is $A_{5}$.

For the case that the attribute weight vector is unknown completely, the weights can be determined as $W=(0.1562,0.1694,0.1627,0.1847,0.1689,0.1581)$ by using Eq. (17). The weighted decision matrix $D^{\prime \prime \prime}$ can be calculated as that in Table 12. Calculate the distances of the alternatives' overall evaluation values to $A^{+}$and $A^{-}$to get $d_{1}^{+}=5.1472, d_{2}^{+}=5.0417$, $d_{3}^{+}=5.1232, d_{4}^{+}=5.1561, d_{5}^{+}=5.0748, d_{6}^{+}=5.1121, d_{7}^{+}=5.1304, d_{8}^{+}=5.0833, d_{1}^{-}=0.8528$, $d_{2}^{-}=0.9853, d_{3}^{-}=0.8768, d_{4}^{-}=0.8439, d_{5}^{-}=0.9252, d_{6}^{-}=0.8879, d_{7}^{-}=0.8696, d_{8}^{-}=0.9167$. Then the relative closeness coefficients are determined by using the TOPSIS method to obtain $c_{1}=0.1421, c_{2}=0.1642, \quad c_{3}=0.1461, c_{4}=0.1407, c_{5}=0.1542, c_{6}=0.1480, c_{7}=$ 
Table 11. Intuitionistic fuzzy weighted decision matrix $D^{\prime \prime}$

\begin{tabular}{ccccccc}
\hline & $B_{1}$ & $B_{2}$ & $B_{3}$ & $B_{4}$ & $B_{5}$ & $B_{6}$ \\
\hline$A_{1}$ & $(0.0676,0.9167)$ & $(0.2726,0.6283)$ & $(0.1685,0.7904)$ & $(0.0938,0.7894)$ & $(0.0814,0.8852)$ & $(0.0326,0.9379)$ \\
\hline$A_{2}$ & $(0.0427,0.8735)$ & $(0.0971,0.8065)$ & $(0.1002,0.8527)$ & $(0.2974,0.6564)$ & $(0.1059,0.8618)$ & $(0.1317,0.8450)$ \\
\hline$A_{3}$ & $(0.0679,0.8763)$ & $(0.1440,0.7673)$ & $(0.0475,0.9012)$ & $(0.2191,0.6762)$ & $(0.0798,0.8623)$ & $(0.0832,0.8532)$ \\
\hline$A_{4}$ & $(0.1221,0.8425)$ & $(0.1484,0.7478)$ & $(0.1472,0.8094)$ & $(0.1228,0.7204)$ & $(0.0342,0.9138)$ & $(0.0463,0.9324)$ \\
\hline$A_{5}$ & $(0.0355,0.9226)$ & $(0.2572,0.6738)$ & $(0.0690,0.8871)$ & $(0.2870,0.6550)$ & $(0.0698,0.8443)$ & $(0.0589,0.8588)$ \\
\hline$A_{6}$ & $(0.0637,0.9170)$ & $(0.3780,0.5895)$ & $(0.0426,0.9136)$ & $(0.1499,0.7375)$ & $(0.1119,0.8171)$ & $(0.0497,0.9387)$ \\
\hline$A_{7}$ & $(0.0286,0.9321)$ & $(0.2033,0.6854)$ & $(0.1476,0.7845)$ & $(0.1518,0.7471)$ & $(0.0342,0.0978)$ & $(0.1083,0.8557)$ \\
\hline$A_{8}$ & $(0.0715,0.8956)$ & $(0.0781,0.8212)$ & $(0.1139,0.8310)$ & $(0.2526,0.6836)$ & $(0.1737,0.7999)$ & $(0.0286,0.9276)$ \\
\hline
\end{tabular}

Table 12. Intuitionistic fuzzy weighted decision matrix $D^{\prime \prime \prime}$

\begin{tabular}{ccccccc}
\hline & $B_{1}$ & $B_{2}$ & $B_{3}$ & $B_{4}$ & $B_{5}$ & $B_{6}$ \\
\hline$A_{1}$ & $(0.1036,0.8730)$ & $(0.1751,0.7549)$ & $(0.1814,0.7748)$ & $(0.0702,0.8397)$ & $(0.1126,0.8423)$ & $(0.0510,0.9037)$ \\
\hline$A_{2}$ & $(0.0659,0.8096)$ & $(0.0599,0.8780)$ & $(0.1082,0.8413)$ & $(0.2296,0.7326)$ & $(0.1458,0.8111)$ & $(0.2001,0.7663)$ \\
\hline$A_{3}$ & $(0.1040,0.8135)$ & $(0.0898,0.8519)$ & $(0.0515,0.8932)$ & $(0.1670,0.7489)$ & $(0.1105,0.8118)$ & $(0.1283,0.7780)$ \\
\hline$A_{4}$ & $(0.1841,0.7651)$ & $(0.0926,0.8388)$ & $(0.1587,0.7950)$ & $(0.0923,0.7848)$ & $(0.0477,0.8808)$ & $(0.0722,0.8953)$ \\
\hline$A_{5}$ & $(0.0549,0.8818)$ & $(0.1646,0.7875)$ & $(0.0746,0.8781)$ & $(0.2212,0.7315)$ & $(0.0968,0.7881)$ & $(0.0915,0.7861)$ \\
\hline$A_{6}$ & $(0.0977,0.8733)$ & $(0.2497,0.7263)$ & $(0.0461,0.9066)$ & $(0.1131,0.7985)$ & $(0.1538,0.7526)$ & $(0.0774,0.9048)$ \\
\hline$A_{7}$ & $(0.0444,0.8959)$ & $(0.1285,0.7957)$ & $(0.1591,0.7685)$ & $(0.1146,0.8065)$ & $(0.0478,0.8728)$ & $(0.1657,0.7817)$ \\
\hline$A_{8}$ & $(0.1095,0.8418)$ & $(0.0480,0.8876)$ & $(0.1230,0.8181)$ & $(0.1936,0.7550)$ & $(0.2355,0.7304)$ & $(0.0448,0.8880)$ \\
\hline
\end{tabular}

$0.1449, c_{8}=0.1528$. Since the ranking of relative closeness coefficients is $c_{2}>c_{8}>c_{5}>c_{6}>$ $c_{3}>c_{7}>c_{4}>c_{1}$, the ranking of alternatives can thus be determined as $A_{2}>A_{8}>A_{5}>A_{6}>$ $A_{3}>A_{7}>A_{4}>A_{1}$. The optimal alternative is $A_{2}$.

From the above results, we can see that the proposed new algorithm can be used to solve real decision making problems. By making use of the TOPSIS method to determine weights of evaluation values given by different decision makers, the influence of unduly high or low evaluation values on the ranking results can be reduced and more reasonable and scientific decisions can be made. The algorithm has been proposed considering different situations about attribute weight information. The overall computation amount of the new algorithm is small. Though a relatively simple MAGDM problem is presented to illustrate the feasibility and efficiency of the proposed algorithm, the new algorithm is very well suitable for solving large-scale and complicated decision making problems.

In order to further illustrate the practical advantages of the proposed method, we apply it to a real decision problem, the evaluation of the murals in Xian Metro Line 2, Xian, China.

Example 2. Due to the economic development and urbanization, the transportation demand increases rapidly in Xian. Like that in other metropolis, the subway has become an inevitable choice for Xian since it is comfortable, timely, and can avoid road congestion, parking difficulty, etc. Xi'an Metro Line 2 has been operating for one year. Due to the 
specific underground traffic space, the subway space is suffering from the lack of natural light and fresh air, noise, humidity, lose of direction, and so on. As an important part of the direction indicator system, the mural is very useful for showing directions and beautifying the metro environment, it can also regulate the visual and spatial environment, and cultivate passengers' aesthetic feeling. Moreover, the murals can demonstrate the typical characteristics of Xian as a famously historical and cultural city. For the above reasons, we use the proposed algorithm to evaluate the murals in Xian Metro Line 2. The results can provide insightful guidance for other subways in Xian. We select the following four paintings to evaluate: $A_{1}$ - Yu Shou, $A_{2}-$ Da Qin Qiang, $A_{3}-$ Ying Bin Tu, $A_{4}-$ Qin Ling Si Bao. We consider the following attributes: $B_{1}$ - affinity, $B_{2}$ - diversity, $B_{3}$-artistry, $B_{4}-$ acceptability, $B_{5}$ - orientation. Three experts from different fields are invited to evaluate the paintings.

The attribute weight vector is known exactly as $W=(0.15,0.20,0.35,0.10,0.20)$, then the proposed algorithm is used to rank the murals.

Step 1. The experts evaluate the four murals in the Xi'an Metro Line 2 by intuitionistic fuzzy values and the results are shown in Tables 13-15.

Step 2. Determine the intuitionistic fuzzy positive ideal decision matrix and the intuitionistic fuzzy negative ideal decision matrices by using the Eqs (5)-(7).

Step 3. Calculate the evaluation values' weights by using Eqs (8)-(12) and calculate the collective matrix by using the IFWA operator as Eq. (13), the result is given in Table 16.

Table 13. Intuitionistic fuzzy decision matrix $E^{(1)}$

\begin{tabular}{cccccc}
\hline & $B_{1}$ & $B_{2}$ & $B_{3}$ & $B_{4}$ & $B_{5}$ \\
\hline$A_{1}$ & $(0.6,0.2)$ & $(0.8,0.1)$ & $(0.3,0.4)$ & $(0.6,0.2)$ & $(0.4,0.5)$ \\
\hline$A_{2}$ & $(0.3,0.5)$ & $(0.4,0.4)$ & $(0.7,0.2)$ & $(0.4,0.1)$ & $(0.5,0.3)$ \\
\hline$A_{3}$ & $(0.4,0.5)$ & $(0.3,0.6)$ & $(0.6,0.3)$ & $(0.7,0.3)$ & $(0.5,0.2)$ \\
\hline$A_{4}$ & $(0.3,0.3)$ & $(0.6,0.2)$ & $(0.4,0.3)$ & $(0.4,0.2)$ & $(0.7,0.1)$ \\
\hline
\end{tabular}

Table 14. Intuitionistic fuzzy decision matrix $E^{(2)}$

\begin{tabular}{cccccc}
\hline & $B_{1}$ & $B_{2}$ & $B_{3}$ & $B_{4}$ & $B_{5}$ \\
\hline$A_{1}$ & $(0.5,0.3)$ & $(0.8,0.2)$ & $(0.3,0.4)$ & $(0.7,0.2)$ & $(0.5,0.5)$ \\
\hline$A_{2}$ & $(0.4,0.5)$ & $(0.5,0.4)$ & $(0.7,0.3)$ & $(0.5,0.2)$ & $(0.5,0.2)$ \\
\hline$A_{3}$ & $(0.4,0.4)$ & $(0.3,0.5)$ & $(0.6,0.2)$ & $(0.6,0.3)$ & $(0.6,0.2)$ \\
\hline$A_{4}$ & $(0.3,0.2)$ & $(0.6,0.3)$ & $(0.4,0.4)$ & $(0.4,0.3)$ & $(0.7,0.2)$ \\
\hline
\end{tabular}

Table 15. Intuitionistic fuzzy decision matrix $E^{(3)}$

\begin{tabular}{cccccc}
\hline & $B_{1}$ & $B_{2}$ & $B_{3}$ & $B_{4}$ & $B_{5}$ \\
\hline$A_{1}$ & $(0.4,0.2)$ & $(0.7,0.3)$ & $(0.4,0.3)$ & $(0.6,0.1)$ & $(0.4,0.4)$ \\
\hline$A_{2}$ & $(0.5,0.5)$ & $(0.4,0.3)$ & $(0.8,0.2)$ & $(0.5,0.3)$ & $(0.5,0.3)$ \\
\hline$A_{3}$ & $(0.2,0.3)$ & $(0.4,0.6)$ & $(0.5,0.3)$ & $(0.7,0.2)$ & $(0.6,0.2)$ \\
\hline$A_{4}$ & $(0.3,0.4)$ & $(0.5,0.4)$ & $(0.3,0.4)$ & $(0.4,0.1)$ & $(0.8,0.1)$ \\
\hline
\end{tabular}


Table 16. Intuitionistic fuzzy decision matrix $E$

\begin{tabular}{cccccc}
\hline & $B_{1}$ & $B_{2}$ & $B_{3}$ & $B_{4}$ & $B_{5}$ \\
\hline$A_{1}$ & $(0.5073,0.2354)$ & $(0.7759,0.1777)$ & $(0.3309,0.3677)$ & $(0.6220,0.1452)$ & $(0.4214,0.4522)$ \\
\hline$A_{2}$ & $(0.4060,0.5000)$ & $(0.4213,0.3512)$ & $(0.7375,0.2268)$ & $(0.4604,0.1635)$ & $(0.5000,0.2658)$ \\
\hline$A_{3}$ & $(0.3507,0.4008)$ & $(0.3287,0.5569)$ & $(0.5700,0.2649)$ & $(0.6718,0.2625)$ & $(0.5723,0.2000)$ \\
\hline$A_{4}$ & $(0.3000,0.2876)$ & $(0.5738,0.2853)$ & $(0.3692,0.3632)$ & $(0.4000,0.1800)$ & $(0.7377,0.1237)$ \\
\hline
\end{tabular}

Steps 4 and 5. Calculate the weighted decision matrix by $\alpha_{i j}^{\prime}=w_{j} \alpha_{i j}$.

Step 6. The distances of collective evaluation values to the intuitionistic fuzzy positive ideal evaluation value $A^{+}$and the intuitionistic fuzzy negative ideal evaluation value $A^{-}$can be determined as follows:

$$
\begin{aligned}
& d_{1}^{+}=4.1344, d_{2}^{+}=4.0994, d_{3}^{+}=4.1866, d_{4}^{+}=4.1104, d_{1}^{-}=0.8656, d_{2}^{-}=0.9006, \\
& d_{3}^{-}=0.8134, d_{4}^{-}=0.8896 .
\end{aligned}
$$

Step 7. Calculate the relative closeness coefficients by using Eq. (22) and the results are as follows:

$c_{1}=0.1731, c_{2}=0.1801, c_{3}=0.1627, c_{4}=0.1779$.

Rank the relative closeness coefficients to get $c_{2}>c_{4}>c_{1}>c_{3}$. The alternatives can be ranked accordingly $A_{2}>A_{4}>A_{1}>A_{3}$, thus the optimal alternative is $A_{2}$.

Da Qin Qiang has been selected as the best painting since it has high artistry and can show the cultural characteristics of Xi'an. This explains the reasonability of the evaluation result and the practicality of our algorithm. The ranking results can provide references since several other subways are under construction in Xian.

\section{Conclusions}

In this paper, a new algorithm based on the TOPSIS method in intuitionistic fuzzy setting is introduced. The weights of evaluation values given by different decision makers are determined by utilizing the TOPSIS technique, which has the advantages that the evaluation value close to the mean one has a large weight and the evaluation value far from the mean one has a small weight. The new weights can reduce the influence of unduly high or low evaluation values on the ranking result. Different situations about the attribute weight information are considered. If the attribute weights are known incompletely, a linear programming model is set up to determine attribute weights by maximizing the weighted relative closeness coefficients. For the situation with completely unknown attribute weights, the weights can be determined according to the principle that the attribute whose evaluation value is close to the positive ideal evaluation and far from negative ideal evaluation values has a large weight. The corresponding algorithm has been designed considering different attribute weight situations. Two real examples are finally given to illustrate the efficiency and practical advantages of the new algorithm. As the results in Tables 8-11 show, the collective evaluation values obtained by the proposed algorithm are different from the weights determined beforehand, and different decision makers' different weights determined by TOPSIS can avoid the influence of unreasonable evaluation values to the ranking result. Hence the results are more reasonable than those obtained by existing methods. 
The proposed method and algorithm can be generalized to the interval-valued intuitionistic fuzzy setting. As for the future study, our new algorithm could be further enhanced by considering other aspects of uncertainty existing in decision problems. It is also interesting to apply our algorithm to solve other complex MAGDM problems.

\section{Acknowledgements}

The authors deeply thank four anonymous referees and the associate editor for their helpful remarks, which have helped us to improve the paper in both content and style. This research was partially supported by the National Natural Science Foundation of China (Nos. 70971109, 71371152, 11401457, 11326204, 11571270), the Natural Science Foundation of Shaanxi Province (Nos. 2014JQ1019, 2014JM1010).

\section{References}

Atanassov, K. 1986. Intuitionistic fuzzy sets, Fuzzy Sets and Systems 20(1): 87-96. http://dx.doi.org/10.1016/S0165-0114(86)80034-3

Atanassov, K.; Pasi, G.; Yager, R. R. 2005. Intuitionistic fuzzy interpretations of multi-criteria multiperson and multi-measurement tool decision making, International Journal of Systems Science 36(14): 859-868. http://dx.doi.org/10.1080/00207720500382365

Boran, F. E.; Genç, S.; Kurt, M.; Akay, D. 2009. A multi-criteria intuitionistic fuzzy group decision making for supplier selection with TOPSIS method, Expert Systems with Applications 36(8): 1136311368. http://dx.doi.org/10.1016/j.eswa.2009.03.039

Brock, H. W. 1980. The problem of utility weights' in group preference aggregation, Operations Research 28(1): 176-187. http://dx.doi.org/10.1287/opre.28.1.176

Chen, S. M.; Niou, S. J. 2011. Fuzzy multiple attributes group decision-making based on fuzzy induced OWA operators, Expert Systems with Applications 38(4): 4097-4108. http://dx.doi.org/10.1016/j.eswa.2010.09.073

Chen, S. M.; Tan, J. M. 1994. Handling multi-criteria fuzzy decision-making problems based on vague sets, Fuzzy Sets and Systems 67(2): 163-172. http://dx.doi.org/10.1016/0165-0114(94)90084-1

Chen, S. M.; Yang, M. W.; Lee, L. W.; Yang, S. W. 2012. Fuzzy multiple attributes group decision making based on ranking interval type-2 fuzzy sets, Expert Systems with Applications 39(5): 5295-5308. http://dx.doi.org/10.1016/j.eswa.2011.11.008

Chen, Z. P.; Yang, W. 2011a. A new multiple attribute group decision making method in intuitionistic fuzzy setting, Applied Mathematical Modelling 35(9): 4424-4437. http://dx.doi.org/10.1016/j.apm.2011.03.015

Chen, Z. P.; Yang, W. 2011b. An MAGDM based on constrained FAHP and FTOPSIS and its application to supplier selection, Mathematical and Computer Modelling 54(11-12): 2802-2815. http://dx.doi.org/10.1016/j.mcm.2011.06.068

Chuu, S. J. 2009. Group decision-making model using fuzzy multiple attributes analysis for the evaluation of advanced manufacturing technology, Fuzzy Sets and Systems 160(1): 586-602. http://dx.doi.org/10.1016/j.fss.2008.07.015

Dymova, L.; Sevastjanov, P.; Tikhonenko, A. 2015. An interval type-2 fuzzy extension of the TOPSIS method using alpha cuts, Knowledge-Based Systems 83: 116-127.

French, S.; Hartley, R.; Thomas, L. C.; White, D. J. 1983. Multi-objective decision making. New York: Academic Press. 
Hajiagha, S. H. R.; Hashemi, S. S.; Zavadskas, E. K. 2013. A complex proportional assessment method for group decision making in an interval-valued intuitionistic fuzzy environment, Technological and Economic Development of Economy 19(1): 22-37. http://dx.doi.org/10.3846/20294913.2012.762953

Herrera, F.; Herrera-Viedma, E.; Verdegay, J. L. 1995. A sequential selection process in group decision making with a linguistic assessment approach, Information Sciences 85(4): 223-239. http://dx.doi.org/10.1016/0020-0255(95)00025-K

Hong, D. H.; Choi, C. H. 2000. Multi-criteria fuzzy decision-making problems based on vague set theory, Fuzzy Sets and Systems 114(1): 103-113. http://dx.doi.org/10.1016/S0165-0114(98)00271-1

Hwang, C. L.; Yoon, K. 1981. Multiple attribute decision making methods and applications. Berlin: Springer. http://dx.doi.org/10.1007/978-3-642-48318-9

Jiang, Y. C.; Tang, Y.; Liu, H.; Chen, Z. Z. 2013. Entropy on intuitionistic fuzzy soft sets and on intervalvalued fuzzy soft sets, Information Sciences 240: 95-114. http://dx.doi.org/10.1016/j.ins.2013.03.052

Keeney, R. L.; Kirkwood, C. W. 1975. Group decision making using cardinal social welfare functions, Management Science 22(4): 430-437. http://dx.doi.org/10.1287/mnsc.22.4.430

Kim, S. H.; Choi, S. H.; Kim, J. K. 1999. An interactive procedure for multiple attribute group decision making with incomplete information: range-based approach, European Journal of Operational Research 118(1): 139-152. http://dx.doi.org/10.1016/S0377-2217(98)00309-9

Li, D. F. 2007. Compromise ratio method for fuzzy multi-attribute group decision making, Applied Soft Computing 7(3): 807-817. http://dx.doi.org/10.1016/j.asoc.2006.02.003

Li, D. F.; Wang, Y. C.; Liu, S.; Shan, F. 2009. Fractional programming methodology for multiattribute group decision-making using IFS, Applied Soft Computing 9(1): 219-225.

http://dx.doi.org/10.1016/j.asoc.2008.04.006

Lin, Y. H.; Lee, P. C.; Chang, T. P.; Ting, H. I. 2008. Multi-attribute group decision making model under the condition of uncertain information, Automation in Construction 17(6): 792-797. http://dx.doi.org/10.1016/j.autcon.2008.02.011

Liu, H. W.; Wang, G. J. 2007. Multi-criteria decision-making methods based on intuitionistic fuzzy sets, European Journal of Operational Research 179(1): 220-233. http://dx.doi.org/10.1016/j.ejor.2006.04.009

Liu, P. D. 2011. A weighted aggregation operators multi-attribute group decision-making method based on interval-valued trapezoidal fuzzy numbers, Expert Systems with Applications 38: 1053-1060. http://dx.doi.org/10.1016/j.apm.2011.09.006

Liu, P. D. 2012. An approach to group decision making based on 2-dimension uncertain linguistic information, Technological and Economic Development of Economy 18(3): 424-437. http://dx.doi.org/10.3846/20294913.2012.702139

Liu, S.; Chan, F. T. S.; Ran, W. X. 2013. Multi-attribute group decision-making with multi-granularity linguistic assessment information: An improved approach based on deviation and TOPSIS, Applied Mathematical Modelling 37(24): 10129-10140. http://dx.doi.org/10.1016/j.apm.2013.05.051

Lourenzutti, R.; Krohling, R. A. 2014. The Hellinger distance in multicriteria decision making: an illustration to the TOPSIS and TODIM methods, Expert Systems with Applications 41(9): 4414-4421. http://dx.doi.org/10.1016/j.eswa.2014.01.015

Maji, P. K.; Biswas, R.; Roy, A. R. 2001. Intuitionistic fuzzy soft sets, Journal of Fuzzy Mathematics 9(3): 677-692.

Merigó, J. M.; Gil-Lafuente, A. M. 2011. Fuzzy induced generalized aggregation operators and its application in multi-person decision making, Expert Systems with Applications 38(8): 9761-9772. http://dx.doi.org/10.1016/j.eswa.2011.02.023

Merigó, J. M.; Gil-Lafuente, A. M. 2013. Induced 2-tuple linguistic generalized aggregation operators and their application in decision-making, Information Sciences 236: 1-16.

http://dx.doi.org/10.1016/j.ins.2013.02.039 
Ngwenyama, O.; Bryson, N. 1999. Eliciting and mapping qualitative preferences to numeric ranking in group decision making, European Journal of Operational Research 116(3): 487-497. http://dx.doi.org/10.1016/S0377-2217(98)00081-2

Olcer, A. I.; Odabasi, A. Y. 2005. A new fuzzy multiple attributive group decision making methodology and its application to propulsion/manoeuvring system selection problem, European Journal of Operational Research 166(1): 93-114. http://dx.doi.org/10.1016/j.ejor.2004.02.010

Pang, J. F.; Liang, J. Y. 2012. Evaluation of the results of multi-attribute group decision-making with linguistic information, Omega 40(3): 294-301. http://dx.doi.org/10.1016/j.omega.2011.07.006

Park, J. H.; Park, I. Y.; Kwun, Y. C.; Tan, X. G. 2011. Extension of the TOPSIS method for decision making problems under interval-valued intuitionistic fuzzy environment, Applied Mathematical Modelling 35(5): 2544-2556. http://dx.doi.org/10.1016/j.apm.2010.11.025

Patil, S. K.; Kant, R. 2014. A fuzzy AHP-TOPSIS framework for ranking the solutions of Knowledge Management adoption in Supply Chain to overcome its barriers, Expert Systems with Applications 41(2): 679-693. http://dx.doi.org/10.1016/j.eswa.2013.07.093

Ramanathan, R.; Ganesh, L. S. 1994. Group preference aggregation methods employed in AHP: an evaluation and an intrinsic process for deriving members weightages, European Journal of Operational Research 79(2): 249-265. http://dx.doi.org/10.1016/0377-2217(94)90356-5

Ran, L. G.; Wei G. W. 2015. Uncertain prioritized operators and their application to multiple attribute group decision making, Technological and Economic Development of Economy 21(1): 118-139. http://dx.doi.org/10.3846/20294913.2014.979454

Su, W. H.; Zeng, S. Z.; Ye, X. J. 2013. Uncertain group decision-making with induced aggregation operators and Euclidean distance, Technological and Economic Development of Economy 19(3): 431-447. http://dx.doi.org/10.3846/20294913.2013.821686

Su, Z. X.; Chen, M. Y.; Xia, G. P.; Wang, L. 2011. An interactive method for dynamic intuitionistic fuzzy multi-attribute group decision making, Expert Systems with Applications 38(12): 15286-15295. http://dx.doi.org/10.1016/j.eswa.2011.06.022

Szmidt, E.; Kacprzyk, J.; Bujnowski, P. 2014. How to measure the amount of knowledge conveyed by Atanassov's intuitionistic fuzzy sets, Information Sciences 257: 276-285. http://dx.doi.org/10.1016/j.ins.2012.12.046

Tan C. Q. 2011. A multi-criteria interval-valued intuitionistic fuzzy group decision making with Choquet integral-based TOPSIS, Expert Systems with Applications 38(4): 3023-3033. http://dx.doi.org/10.1016/j.eswa.2010.08.092

Taylan, O.; Bafail, A. O.; Abdulaal, R. M. S.; Kabli, M. R. 2014. Construction projects selection and risk assessment by fuzzy AHP and fuzzy TOPSIS methodologies, Applied Soft Computing 17: 105-116. http://dx.doi.org/10.1016/j.asoc.2014.01.003

Wang, W. Z.; Liu, X. W.; Qin, Y. 2012. Multi-attribute group decision making models under interval type-2 fuzzy environment, Knowledge-Based Systems 30: 121-128.

http://dx.doi.org/10.1016/j.knosys.2012.01.005

Wei, G. W. 2010. A method for multiple attribute group decision making based on the ET-WG and ET-OWG operators with 2-tuple linguistic information, Expert Systems with Applications 37(12): 7895-7900. http://dx.doi.org/10.1016/j.eswa.2010.04.047

Wei, G. W. 2011. Some generalized aggregating operators with linguistic information and their application to multiple attribute group decision making, Computers \& Industrial Engineering 61(1): 32-38. http://dx.doi.org/10.1016/j.cie.2011.02.007

Wei, G. W.; Merigó, J. M. 2012. Methods for strategic decision-making problems with immediate probabilities in intuitionistic fuzzy setting, Scientia Iranica 19(6): 1936-1946.

http://dx.doi.org/10.1016/j.scient.2012.07.017 
Wu, Z. B.; Chen, Y. H. 2007. The maximizing deviation method for group multiple attribute decision making under linguistic environment, Fuzzy Sets and Systems 158(14): 1608-1617. http://dx.doi.org/10.1016/j.fss.2007.01.013

Xu, Y. J.; Merigó, J. M.; Wang, H. M. 2012. Linguistic power aggregation operators and their application to multiple attribute group decision making, Applied Mathematical Modelling 36(11): 5427-5444. http://dx.doi.org/10.1016/j.apm.2011.12.002

Xu, Z. S. 2007. Intuitionistic fuzzy aggregation operators, IEEE Transaction on Fuzzy Systems 15: 11791187. http://dx.doi.org/10.1109/TFUZZ.2006.890678

$\mathrm{Xu}, \mathrm{Z}$. S. 2010. A deviation-based approach to intuitionistic fuzzy multiple attribute group decision making, Group Decision and Negotiation 19(1): 57-76. http://dx.doi.org/10.1007/s10726-009-9164-Z

Xu, Z. S.; Liao H. C. 2015. A survey of approaches to decision making with intuitionistic fuzzy preference relations, Knowledge-Based Systems 80: 131-142. http://dx.doi.org/10.1016/j.knosys.2014.12.034

Yang, W.; Chen, Z. P. 2012. The quasi-arithmetic intuitionistic fuzzy OWA operators, Knowledge-Based Systems 27: 219-233. http://dx.doi.org/10.1016/j.knosys.2011.10.009

Ye, F. 2010. An extended TOPSIS method with interval-valued intuitionistic fuzzy numbers for virtual enterprise partner selection, Expert Systems with Applications 37(10): 7050-7055.

http://dx.doi.org/10.1016/j.eswa.2010.03.013

Yue, Z. L. 2011. A method for group decision-making based on determining weights of decision makers using TOPSIS, Applied Mathematical Modelling 35(4): 1926-1936. http://dx.doi.org/10.1016/j.apm.2010.11.001

Yue, Z. L. 2012. Extension of TOPSIS to determine weight of decision maker for group decision making problems with uncertain information, Expert Systems with Applications 39(7): 6343-6350. http://dx.doi.org/10.1016/j.eswa.2011.12.016

Zadeh, L. A. 1965. Fuzzy sets, Information Control 8(3): 338-353. http://dx.doi.org/10.1016/S0019-9958(65)90241-X

Zhang, H. M.; Yu, L. Y. 2012. MADM method based on cross-entropy and extended TOPSIS with interval-valued intuitionistic fuzzy sets, Knowledge-Based Systems 30: 115-120.

http://dx.doi.org/10.1016/j.knosys.2012.01.003

Wei YANG. Doctor, Associated Professor at Department of Mathematics, School of Science, Xi'an University of Architecture and Technology. She has contributed over 20 journal articles to professional journals such as Knowledge-Based Systems, Expert Systems with Applications, Applied Mathematical Modelling, etc. Her current research interests include multi-criteria decision making, computing with words, and information sciences.

Zhiping CHEN. Doctor, Professor and Vice-dean at the School of Mathematics and Statistics, Xi'an Jiaotong University. He is the Standing Committee and Executive Director of the Financial Engineering and Financial Risk Management, Branch of the Operations Research Society of China.

Dr Chen has published more than 100 scientific articles and 2 books, his research interests include stochastic optimization, risk management and financial optimization, operations research and its application.

Fang ZHANG. Master, Lecturer at the School of Mathematics and Statistics, Xi'an Jiaotong University. She has published 6 scientific articles, her research interests include robust optimization and financial optimization. 